\title{
The Tree of Character
}

\section{An analysis of the character of college students based on sculpture art Ying Zhao}

Department of art and design, Academy of Fine Arts, Yunnan Normal University, Chenggong, Kunming, Yunnan, China

email:893829008@qq.com

Key words: analysis of the character,sculpture art

Abstract. Through the design topic: creating a sculpture -- "The Tree of My Character", this article guides college students to make corresponding thoughts and appropriate choices when facing selfexploration, interpersonal communication, social adaptation, employment and entrepreneurship, etc. Research is an innovative practice the disciplines of education, art and psychology disciplines.

\section{性格之树 \\ 一一基于雕塑艺术的大学生性格探析 \\ 赵䒯 \\ 云南师范大学美术学院艺术设计系, 呈贡, 昆明, 云南, 中国 \\ email: 893829008@qq.com}

关键词：性格探析；雕塑艺术

中文摘要. 本文通过设计课题: 创作一件雕塑一 “我的性格之树”, 引导大学生在面对自我探 索、人际交往、社会适应、就业创业等方面做出相应的思考和恰当的选择。研究是跨教育、 艺术与心理学学科的创新性实践。

\section{1. 引言}

艺术本身就是自我探索的一部分。本文通过引导大学生制作 “性格之树”，协助大学生 在自我探索、人际交往、社会适应、就业创业方面做出恰当的思考。

\section{2. 雕塑艺术}

雕塑，是雕、刻、塑造的总称。材料多元，如可塑材料：粘土、石膏、树脂等; 可雕刻 材料: 石、木、金属、玉、砖、玛瑙、玻璃钢、砂岩、沙等。雕塑是艺术家内心情感的物化 表现，是三维空间的造型艺术。

\section{3. 性格}

\section{1 性格概念与分类}

黑格尔将性格界定为: “人的完整的个性” ，完整即意味着不是一种或者一个，而是诸 多性格特征融合而成的完整的心灵主体性。本文的性格分类理论是基于九型人格

（Enneagram）和四型性格的。九型人格分类为: 完美型（完美主义者）、助人型（给予 
者）、成就型（实干者）、自我型（悲情浪漫者）、理智型（观察者）、疑惑型（怀疑论 者）、活跃型（享乐主者）、领袖型（保护者）、和平型（调停者）。四型性格则是在九型 人格分类基础上进行的简化的, 分为: 活泼型、力量型、完美型、和平型。四型性格的特征 如图1。

\section{4. 性格之树}

\section{1 主题设定}

本文通过引导大学生设计一件雕塑作品：我的 “性格之树”, 将个人的性格投射在 “树” 上, 进行对自我认识的思考与艺术表达。具体做法是：一、使用性格测试量表分析性格; 二、 绘制 “性格之树” 的设计思维导图; 三、总结性格的词汇，将之抽象或具象化并塑造成为雕 塑; 四、使用材料（木、石、陶土、金属、石膏、纸等），可应用肌理装饰; 五、应用色彩象 征的表现手法。

\subsection{1性格测试}

根据四型性格测试量表测试大学生的性格（图1），以正向优点20分与负向缺点20分做 横向记分, 满分40分, 四栏（活泼型、力量型、完美型、和平型）中, 得分高的选项就是性 格的主要特质, 性格中的正负项并无对错之分。例如: 一名被测得分为: 力量型16分, 活泼 型12分, 完美型7分, 和平型5分, 就判断为力量活泼型性格。被测可能测试出一种或两种以 上的性格特征，因人而异。力量型、完美型以 “任务” 为中心，活泼型、和平型以 “人” 为 中心。

\begin{tabular}{|c|c|c|c|c|c|c|c|c|}
\hline \multicolumn{3}{|c|}{ 活泼型 } & \multicolumn{2}{|c|}{ 力量型 } & \multicolumn{2}{|c|}{ 完美型 } & \multicolumn{2}{|c|}{ 和平型 } \\
\hline 序号 & 正 & 负 & 正 & 负 & 正 & 负 & 正 & 负 \\
\hline 1 & 生动 & 露骨 & 富於冒险 & 专横 & 善于分析 & 扭捏 & 适应力强 & 乏味 \\
\hline 2 & 喜好娱乐 & 散漫 & 善于说服 & 无同情心 & 体贴 & 不宽恕 & 平和 & 缺乏热情 \\
\hline 3 & 善于社交 & 唠叨 & 竞争性 & 逆反 & 受尊重 & 怨恨 & 顺服 & 保留 \\
\hline 4 & 使人认同 & 健忘 & 善于应变 & 率直 & 敏感 & 挑剔 & 有自控力 & 胆小 \\
\hline 5 & 使人振作 & 好插嘴 & 自立 & 急躁 & 策划者 & 无安全感 & 含蓄 & 优柔寡断 \\
\hline 6 & 生气勃勃 & 难预测 & 积极 & 缺乏同情心 & 有时间性 & 不受欢迎 & 耐性 & 不参与 \\
\hline 7 & 推动者 & 善变 & 肯定 & 固执 & 井井有条 & 难于取悦 & 差澀 & 犹豫不觉 \\
\hline 8 & 无拘无束 & 即兴 & 坦率 & 鲁莽 & 忠诚 & 悲观 & 迁就 & 平淡 \\
\hline 9 & 乐观 & 放任 & 强迫性 & 自负 & 注意细节 & 消极 & 友善 & 无目标 \\
\hline 10 & 有趣 & 易怒 & 勇敢 & 好争吵 & 文化修养 & 孤芳自赏 & 外交手腕 & 冷漠 \\
\hline 11 & 可爱 & 天真 & 自信 & 工作狂 & 理想主义 & 不善交际 & 贯彻始终 & 担忧 \\
\hline 12 & 令人高兴 & 喜获认同 & 独立 & 不圆滑老练 & 深沉 & 过分敏感 & 无攻击性 & 胆怯 \\
\hline 13 & 富激励性 & 喋喋不休 & 果断 & 跋扈 & 音乐性 & 抑有 & 尖刻幽默 & 腼腆 \\
\hline 14 & 感情外露 & 生活紊乱 & 发起者 & 不容忍 & 考虑周到 & 内向 & 调节者 & 喃喃自语 \\
\hline 15 & 喜交朋友 & 缺乏毅力 & 执着 & 喜操纵 & 忠心 & 情绪化 & 容忍 & 缓慢 \\
\hline
\end{tabular}




\begin{tabular}{|c|c|c|c|c|c|c|c|c|}
\hline 16 & 多言 & 好表现 & 领导者 & 顽固 & 制图者 & 有戒心 & 聆听者 & 懒惰 \\
\hline 17 & 活力充沛 & 杂乱无章 & 首领 & 统治欲 & 完美主义 & 孤僻 & 知足 & 拖延 \\
\hline 18 & 惹人喜爱 & 不专注 & 勤劳 & 易怒 & 规范性 & 多疑 & 和气 & 妥协 \\
\hline 19 & 受欢迎 & 嗓门大 & 无畏 & 轻率 & 坚持不解 & 报复型 & 平衡 & 无异议 \\
\hline 20 & 跳跃型 & 烦躁 & 意志坚定 & 狡猬 & 自我牺牲 & 好批评 & 满足 & 勉强 \\
\hline
\end{tabular}

图1 四型性格测试量表（《性格之树》美/佛罗伦斯・妮蒂雅）

\subsection{2 绘制思维导图}

思维导图是东尼・拔赞提出的 “大脑的使用说明书”。本课题中，性格与设计思路在思维 导图中一目了然, 同时训练了大学生的发散性思维能力。例如: 图2-1, 图3-1, 图4-1, 图5-1, 图6-1。

\subsection{3 词汇的形象化与造型}

将量表测试结果中的词汇做形象化的设计, 再使用抽象或具象的立体元素造型。例如: 图1-2, 活泼感抽象为突出的多个造型。图3-1, 螺旋形代表凡是追求规矩与完美。

\subsection{4 材料应用}

图5-2使用金属丝为材料，多根金属丝代表完美型的注意细节与敏感，顶端发射状的造型 表达力量型的易怒、逆反、独立, 呈现的是完美力量型性格。

\subsection{5 色彩应用}

使用色彩的象征表达完成色彩设计。图2-1, 绿色代表缺点: 自我为中心、逃避问题等, 褐色代表优点: 热情、多言、自信、外向。图3-2, 黄色、绿色分别代表力量、有生命、希望 和冷静。图4-2, 五彩的颜色代表 “我的性格天生活泼”。图5-2, 金色代表完美主义、力量, 银色代表坚持不解、平和。

\section{2 大学生的性格探析}

大学生的性格形成多与养育者有极大的关系。例如: 活泼力量型的母亲与 完美型的父亲所养育的小孩会具备其中的某项或多项性格特质。力量型的父亲养育的孩子幼 时呈和平型性格, 但成年后却呈力量型性格, 这是由于力量型父亲的 “控制” 让孩子明白只 有 “乘巧” 才会讨人喜爱, 想要获得更多的认同而形成 “伪装性格”。大学生在完成性格量 表测试的过程中, 若感到有疑惑的词汇应请亲人、养育者或亲近的朋友协助做出更准确的判 断。

每一种性格都有正负两面, 并无对错之分。大学生在处理人际关系、社会适应、团队建 设、就业创业中, 可应用性格分析做出相应的判断。例如: 力量型性格较适合做领导与开拓 性的工作, 缺点是跋扈、无同情心; 完美型性格较适合做策划、执行管理、研究、有深度的 工作, 缺点是比较挑剔、难以做决定和消极; 活泼型比较适合做公关、销售、表演及创意性 的工作，常以 “开心、好玩为目标” ，缺点是凌乱无序和对 “坚持” 一词感到困难; 和平型 适合做公共关系的工作, 缺点是容易说 “随便” 和无目标、守旧、无发展。但和平型有时比 力量型更易成为领导, 原因是和平型善于处理复杂的人际关系, 人缘好, 力量型却过于跋扈 张扬而导致众叛亲离，无人支持。 


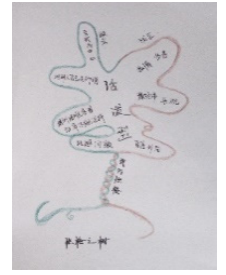

图2-1

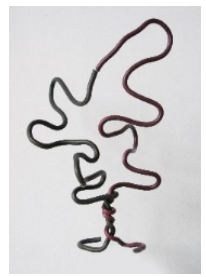

图2-2

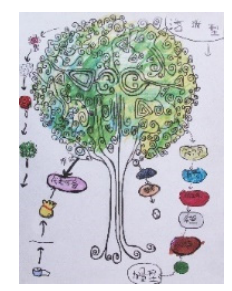

图3-1

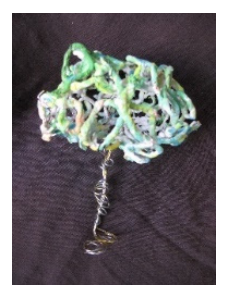

图3-2

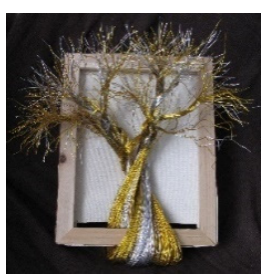

图5-2

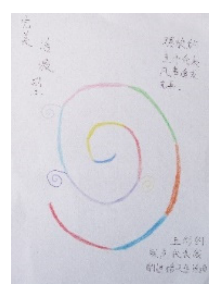

图4-1

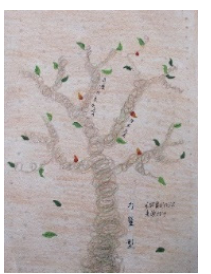

图6-1

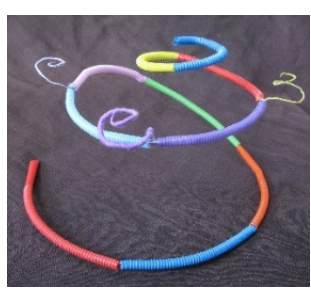

图4-2

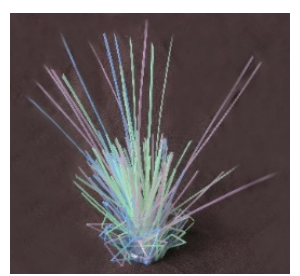

图6-2

\section{5. 结束语}

积极的探索大学生个体的性格, 了解自己和理解他人, 在自我、人际交往、社会适应能 力、就业创业方面做出相应的调整与改变, 是本文的主旨。

\section{References}

[1] Linsheng Zhao, I mean my heart--self-emotional expression in sculpture creation, Thesis for Bachelor's Degree,WuHan university of technology, pp.7, 2015.

[2] Yi Zhao, Chen Duan, A Study of College Students (born after 1995)' Psychological Counseling Method Based on the Nine-type Personality Theory, Coal higher education, vol. 35, pp. 19, 2017.

[3] Florence Nitya, Your Personality Tree, pp.248-249, 2003.

[4] Robert A.Rohm, Positive personality profiles, pp. 24, 2004. 